\title{
Filtration of Cigarette Smoke: Relative Contributions of Inertial Impaction, Diffusional Deposition, and Direct Interception*
}

\author{
by J. Ray Overton \\ Research Laboratories, Tennessee Eastman Company, Division of Eastman Kodak Company, \\ Kingsport, Tennessee, USA
}

The physical processes that can remove a smoke particle from an aerosol stream are direct interception, inertial impaction, and diffusional deposition. Electrical and gravitational effects were not considered because they play an insignificant role in the removal of smoke particles (I).

Flgure 1. Flow lines near cylinder lying transverse to flow.

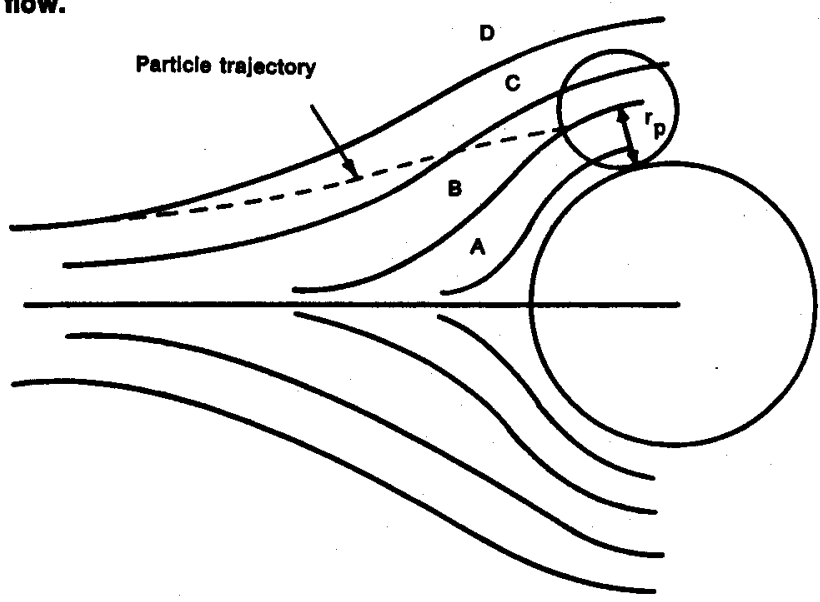

Figure 1 illustrates the streamlines for viscous flow in the vicinity of a cylindrical filament oriented perpendicularly to the smoke-flow direction. Perpendicular orientation is used for illustrative purposes only and does not imply filter construction. If the particle shown with a radius $\mathrm{rP}_{\mathrm{P}}$ is moving along streamline $A$ or B, it will contact a filament in its normal course, a process referred to as direct interception. The usual assumption is that all particle-filament contacts are effective. When a particle is moving along $C$ or $D$, contact with the filament can take place by two processes. In one case, the momentum of the particle will cause it to deviate from the streamline because of its tendency to move in a straight line. If this effect is sufficient, contact can take place, and the particle is removed by inertial impaction. Alternatively, Brownian motion can cause the particle to cross streamlines and come in contact with a filament, which is referred to as diffusional deposition. Impaction is favored by high velocities and large particles; diffusion is favored by small particles and low velocities.

- Received for publication: 25th June, 1973.

\section{DISCUSSION}

\section{Filtration of Smoke Through Standard Cellulose- Acetate Filters}

Smoke filtration in a standard cellulose-acetate filter is considered to occur with all parameters except the smoke velocity held constant. This standard filter is characterized by a packing density (the volume fraction of cellulose acetate in the filter, $\alpha$ ) of 0.094 and a length of $17 \mathrm{~mm}$; it is composed of $3.3 \mathrm{den} . / \mathrm{fil}$. acetate with a \# $10(Y)$ cross section. .

The primary assumption is that filtration can be described by the following relationship (2):

$$
\frac{C}{C_{0}}=e^{-\left[G^{\prime} \cdot f_{1}(v)+D^{\prime} \cdot f_{2}(v)+l^{\prime} \cdot f_{8}(v)\right]} .
$$

$C_{O}$ is the initial concentration of the smoke, and $C$ is the concentration of the smoke penetrating the filter. In this context, penetrating means passing all the way through the filter. The mean velocity of the smoke is $\mathbf{v}$. $G^{\prime}(v), D^{\prime}(v)$, and $l^{\prime}(v)$ are the contributions from impaction, diffusion, and interception. An equation of this type allows the cooperative contribution of three processes that affect the same response.

The relationship between smoke-particle removal and smoke-particle velocity for each of the three mechanisms operating independently is known from theoretical considerations and experimental verification:

1. Inertial impaction is proportional to $v^{2}$,

2. Diffusional deposition is proportional to $v^{2 / 4}$,

3. Interception is independent of velocity.

Therefore,

$$
\frac{C}{C_{0}}=e^{-\left(G^{\prime} v^{2}+D^{\prime} v^{m / 2}+1^{\prime}\right)}
$$

It is convenient to convert the fraction of smoke particles penetrating the filter $\frac{C}{C_{0}}$ to the percent penetrating the filter, $P$, and to convert to $\log _{10}$, which leads to

$$
2-\log \mathrm{P}=\mathrm{Gv}^{2}+\mathrm{Dv} \mathbf{w}^{\mathrm{N} / 2}+1 \text {. }
$$


Flgure 2. Relationshlp between smoke-particle removal and smoke velocity.

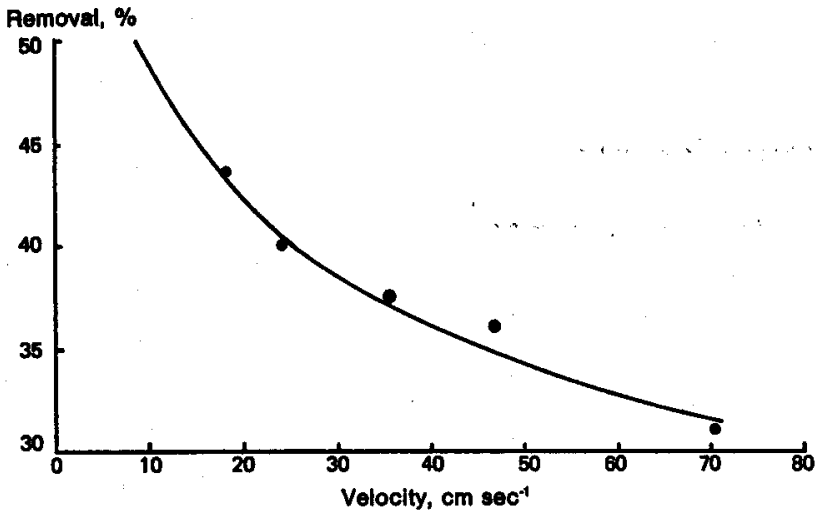

Equation 3 can be simplified in that inertial impaction is very effective at high velocities whereas diffusional deposition is effective at low velocities. Therefore, an intermediate velocity ( $v p$ ) exists where penetration goes through a maximum (percent removal goes through a minimum). Thus, Equation 3 can be differentiated, and

$$
\begin{aligned}
& \frac{\partial P}{\partial v}=0 \text { at } v P \text {. This gives } \\
& \qquad D=3 v P^{8 / 3 G .}
\end{aligned}
$$

Substituting Equation 4 into Equation 3 and D leads to

$$
2-\log P=G\left(v^{2}+3 v P^{2 / 3 v-1 / s}\right)+1 \text {. }
$$

Experimental data on the total removal of smoke particles versus the smoke velocity is shown in Figure 2.

The velocity of maximum penetration $\left(\mathrm{v}_{\mathrm{P}}\right)$ is apparently greater than $70 \mathrm{~cm} \mathrm{sec}^{-1}$. More recent information obtained but not shown in the graph, indicates that vp is greater than $100 \mathrm{~cm} \mathrm{sec}^{-1}$.

Humphrey and Gaden studied the penetration of $I-\mu$ spheres through glass mats composed of $16-\mu$ filaments (3). They found vp to be between 30 and $60 \mathrm{~cm} \mathrm{sec}^{-1}$ Friedlander (4) found that, in general,

$$
v_{P}=K \frac{1}{d_{P}^{8 / 3}}
$$

for any given system where $d_{P}$ is the particle diameter. The 16- $\mu$-diameter filament used by Humphrey was reasonably close to the size of the acetate filaments used in our testing; the major difference between Humphrey's system and ours was particle diameter. If the average particle diameter of cigarette smoke is taken to be $0.5 \mu$, values of 190 to $380 \mathrm{~cm} \mathrm{sec}^{-1}$ are obtained from Humphrey's data and Equation 6. A reasonable estimate of the vp for cigarette smoke is the average of the high and low values, i.e. $285 \mathrm{~cm} \mathrm{sec}^{-1}$.

Equation 5 requires a linear relationship between (2-log P) and $\left(v^{2}+3 v p^{8 / 2} v^{-2 / 3}\right)$, with slope $G$ and intercept 1 . The velocity data from Figure 2 are plotted according to Equation 5 and are shown in Figure 3. Regression analysis of these data gives a slope of $0.77 \times 10^{-i}$ with an intercept of 0.1185 . Substitution of these values into Equation 5 and 4, respectively, leads to

$2-\log P=0.77 \times 10^{-7}\left(v^{2}\right)+0.800 v^{-1 / 3}+0.119$. [7]

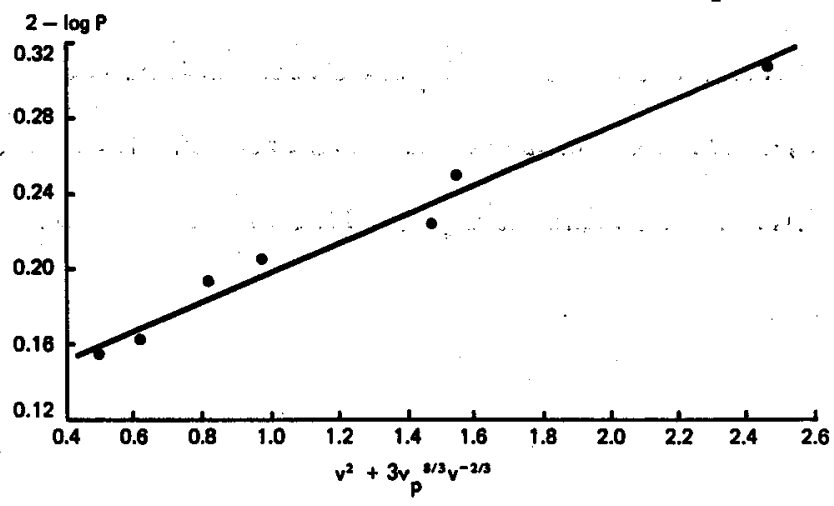

This relationship can be used to predict total smokeparticle removal and the contribution from each mechanism. At a nominal velocity of $35 \mathrm{~cm} \mathrm{sec}^{-1}$, the predicted total removal is $36 \%$. If only diffusion were operative, $16 \%$ would have been removed; interception alone would have removed $24 \%$. Impaction makes no significant contribution in this velocity range. The sum of these contributions is greater than $36 \%$, since all mechanisms operating simultaneously make each appear less effective, based on the original smoke concentration. However, of the total amount removed, $60 \%$ is due to interception, and $40 \%$ is due to diffusion. These relative contributions obviously are different for different velocities: diffusion becomes more important at low velocities, and impaction dominates at very high velocities. The constants in Equation 7 will vary with filament diameter, filament cross section, and perhaps with filament orientation. The effect of filament orientation is discussed later in this paper.

The relative contributions of diffusion and impaction determined by use of the derivative of Equation 3 depend on the value chosen for the velocity of maximum penetration, vP. An alternative method for treating the data is multiple linear regression by use of the equation

$$
y=a x^{2}+b x-2 / 3+c
$$

where the independent variable $x$ represents velocity and the dependent variable $y$ represents $(2-\log P)$. This approach does not impose a VP on the system. From a computer analysis of this multiple linear regression approach, it was concluded that the $x^{2}$ term is not statistically significant; i.e., impaction makes no contribution in this velocity range, and the following relationship is obtained:

$$
2-\log P=0.794 \mathrm{v}^{2 / 2}+0.124 \text {. }
$$

This equation leads to the same result as Equation 7 : diffusion removes $40 \%$ of the total amount of smoke particles removed and interception removes $60 \%$. That Equation 9 leads to the same result as Equation 7 indicates that that value of $285 \mathrm{~cm} \mathrm{sec}^{-1}$ for $v_{P}$ is a good approximation to the true value.

\section{Filtration of Smoke Through Experimental Filters}

The foregoing conclusions are valid only for the kind of system used to obtain the data, i.e. a standard filter 
construction. Another system of interest is one in which the acetate filaments are perpendicular to the direction of flow rather than more or less parallel, as in a standard filter. Special filters with perpendicularly oriented filaments were constructed, and data similar to that from the standard filter were obtained. The techniques previously described were used in the analyses. The value of $285 \mathrm{~cm} \mathrm{sec}^{-1}$, which was used for $\mathrm{VP}_{\mathrm{P}}$, as in the standard filter experiments, led to the following equation:

$$
2-\log P=0.603 \times 10^{-7}\left(v^{2}\right)+0.628 v w / 2+.0904 .
$$

At the nominal velocity of $35 \mathrm{~cm} \mathrm{sec}^{-1}$, a total of $31 \%$ of the smoke was removed; of this amount, $60 \%$ was removed by interception and $40 \%$ by diffusion, the same distribution as in the previous study. Inertial impaction makes no contribution. When the data are treated by multiple linear regression, i.e. without imposing a value of $\mathrm{v}_{\mathrm{P}}$, the following relation is obtained:

$$
2-\log P=0.618 v^{2 / 3}+.0947 .
$$

This is essentially the same as Equation to at low velocities and, of course, gives the same relative distribution of percent removal between the mechanisms. It was concluded that in this experimental velocity range the relative efficiency of the operative mechanisms is independent of filament orientation.

The experimental filters from which the previous data were obtained were constructed to give the same pressure drop as conventional filters, 2.5 in. of water. The total smoke-particle removal by the filaments oriented perpendicularly to the flow direction was less than the removal by the conventional filters, $31 \%$ versus $36 \%$. However, only $65 \%$ of the normal amount of acetate used in the conventional filters was required to prepare the experimental filters with the desired pressure drop. Decreasing the amount of acetate by $35 \%$ decreases the removal by only $14 \%$. Thus, conventional orientation is more efficient based on removal per unit pressure drop, whereas perpendicular orientation is more efficient based on removal per unit mass of cellulose acetate.

\section{Relationship Between Smoke-Particle Removal and Filter-Packing Density}

The packing density $(\alpha)$ is defined as the volume fraction of cellulose acetate in the filter. The velocity profile about a given fiber is altered by the presence of other fibers. Therefore, the efficiency of a given fiber is a function of fiber concentration. In addition, this variation in single fiber efficiency will be different for each of the three mechanisms of smoke particle removal. Under controlled experimental conditions, it was demonstrated that single fiber efficiency varies with packing density in the following manner (5):

1. Impaction $Y_{1}=Y_{01}(1+110 \alpha)$,

2. Diffusion $Y_{2}=Y_{02}(1-4 \alpha)$,

3. Interception $Y_{3}=Y_{03}(1+30 \alpha)$.
Figure 4. Relationship between percent penetration of smoke particles and packing density of the filter.

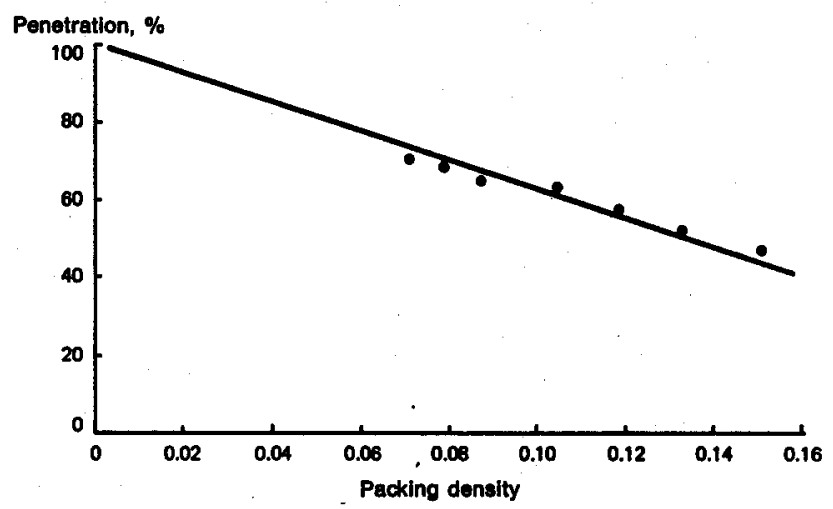

The single fiber efficiency is defined such that the product $\alpha Y_{1}$ is the contribution to the total removal due to impaction at a certain $\alpha$ value. The term $Y_{01}$ is the single fiber efficiency at $\alpha=0$, i. e. for the isolated fiber. For the diffusion term, the single fiber efficiency decreases with increasing packing density. This has been qualitatively explained in terms of a shielding effect for the case of nonparallel orientation (6).

The same form as that used in Equation $I$ is applicable for the relationship between removal and packing density:

$$
\begin{gathered}
\frac{C}{C_{O}}=e^{\alpha\left(y_{1}+y_{2}+y_{3}\right)} \quad \text { or } \\
\frac{C}{C_{O}}= \\
e^{-\alpha\left[y_{01}(1+110 \alpha)+y_{02}(1-4 \alpha)+y_{03}\left(1+y_{00}\right)\right]} .
\end{gathered}
$$

Since the term $y_{01}(1+110 a)$ represents the removal due to impaction at $\alpha$, it can be equated to the impaction term in Equation 7.

$$
\alpha y_{01}(1+100 \alpha)=0.77 \times 10^{-7}\left(v^{2}\right) .
$$

The remaining terms in Equation 13 can also be equated to terms in Equation 7 ; therefore, $y_{01}, y_{02}$, and $y_{03}$ can be evaluated at a given velocity. The calculations for nominal conditions yield the following:

$2-\log P=$

$0.88 \times 10^{-4}(1+110 \alpha) \alpha+1.28(1-4 \alpha) \alpha+0.332(1+30 \alpha) \alpha$.

Summation of terms gives:

$$
2-\log P=1.612 \alpha+4.89 \alpha^{2} .
$$

Equation 15 can be used to predict the smoke particle removal over an extended range of packing densities. Figure 4 illustrates a plot of this relationship, and shows some of the experimental data obtained on a conventional filter. A similar relationship can be derived for the filters made of perpendicularly oriented filaments. Different constants will be obtained but they will be approximately proportional to those obtained for standard filters. 
The results of this analysis suggest that a filter geometry which will allow smoke to pass at a lower than normal velocity is desirable to improve filter efficiency. This improved efficiency is due to the major contribution of the diffusion mechanism and the insignificant contribution of the impaction mechanism to the filtration process. Lower than normal velocities will also reduce the pressure drop. If a filter can be designed to operate at a lower velocity, and therefore at a lower pressure drop, it is desirable to have the acetate filaments oriented perpendicularly to the flow direction of the smoke. This geometry gives higher removal per unit weight of acetate than the geometry of a conventional filter.

\section{ZUSAMMENFASSUNG}

Wie die Ergebnisse der vorliegenden Untersuchung zeigen, ist es für eine Verbesserung der Filterwirksamkeit vorteilhaft, wenn die Filtergeometrie so beschaffen ist, daß der Rauch den Filterstab langsamer durchströmt, als dies normalerweise geschieht. Diese Verbesserung der Filterwirksamkeit beruht darauf, daß überwiegend der Diffusionsmedhanismus und weniger der Ablagerungsmechanismus am Filtrationsproze $\beta$ beteiligt ist. Bei vergleichsweise kleinerer Strömungsgeschwindigkeit ist auch der Zugwiderstand geringer. Wenn ein Filter konstruiert werden kann, der eine geringere Strömungsgeschwindigkeit und damit einen geringeren Zugwiderstand ermöglicht, ist es wünschenswert, daß die Acetatfasern vertikal zum Rauchstrom gelagert sind. Dadurch ergibt sich je Gewichtseinheit Acetat eine höhere selektive Retention als in herkömmlichen Filtern.
Les résultats de cette analyse suggèrent que pour augmenter l'efficacité d'un filtre, il faudrait trouver une géométrie qui permettrait à la fumée de passer à une vitesse plus faible que normale. Cette amélioration d'efficacité est due à la contribution importante du mécanisme de diffusion, et à la contribution insigniflante de l'arrêt par inertie au processus de filtration. Une vitesse plus basse que normale réduira également la résistance au tirage. S'il est possible de concevoir un filtre à vitesse réduite (et donc résistance au tirage réduite) il est souhaitable d'orienter les filaments d'acétate perpendiculairement à la direction du flux de fumée. Cette géométrie permet une rétention sélective plus grande par unité de poids d'acétate que la géométrie conventionelle.

\section{REFERENCES}

I. Davies, C. N., editor: Aerosol science; Academic Press, New York, 1966, p. 324.

2. lbid., p. 215.

3. Humphrey, A., and E. Gaden: Ind. Eng. Chem. 47 (1955) 924.

4. Ibid., C. N. Davies, p. 245.

5. Ibid., C. N. Davies, p. 217.

6. Kirsh, A. A., and N. A. Fuks: Colloid J. (USSR) 30 (1968) 630 .

The author's address:

Tennessee Eastman Company, Research Laboratories, Kingsport, Tennessee, 37662, USA. 